
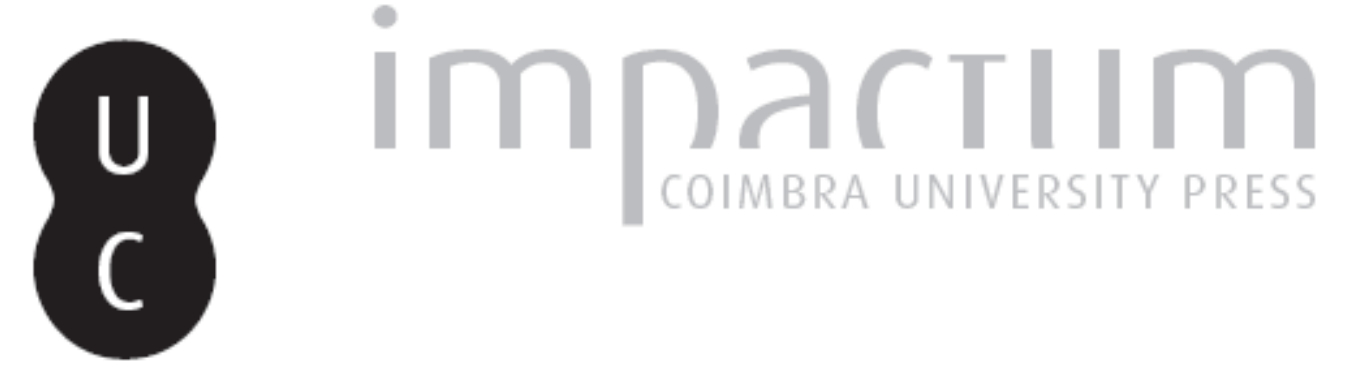

O que parece saber o que não está presente: tema de estudo breve na primeira parte das investigações filosóficas de Wittgenstein

Autor(es): $\quad$ Pais, António de Carvalho

Publicado por: Faculdade de Letras da Universidade de Coimbra, Instituto de Estudos

URL

persistente:

Filosóficos

DOI: $\quad$ DOI:http://dx.doi.org/10.14195/0872-0851_45_10

Accessed : $\quad$ 26-Apr-2023 13:36:42

A navegação consulta e descarregamento dos títulos inseridos nas Bibliotecas Digitais UC Digitalis, UC Pombalina e UC Impactum, pressupõem a aceitação plena e sem reservas dos Termos e Condições de Uso destas Bibliotecas Digitais, disponíveis em https://digitalis.uc.pt/pt-pt/termos.

Conforme exposto nos referidos Termos e Condições de Uso, o descarregamento de títulos de acesso restrito requer uma licença válida de autorização devendo o utilizador aceder ao(s) documento(s) a partir de um endereço de IP da instituição detentora da supramencionada licença.

Ao utilizador é apenas permitido o descarregamento para uso pessoal, pelo que o emprego do(s) título(s) descarregado(s) para outro fim, designadamente comercial, carece de autorização do respetivo autor ou editor da obra.

Na medida em que todas as obras da UC Digitalis se encontram protegidas pelo Código do Direito de Autor e Direitos Conexos e demais legislação aplicável, toda a cópia, parcial ou total, deste documento, nos casos em que é legalmente admitida, deverá conter ou fazer-se acompanhar por este aviso.

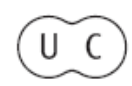




\section{REVISTA FILOSÓFICA DE COIMBRA}

vol. 23 - número 45 - março 2014

vol. 23 - número 45 - março 2014 Fundação Eng. António de Almeida

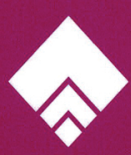




\title{
O QUE PARECE SABER O QUE NÃO ESTÁ PRESENTE: TEMA DE ESTUDO BREVE NA PRIMEIRA PARTE DAS INVESTIGAÇÕES FILOSÓFICAS DE WITTGENSTEIN
}

\author{
ANTÓNIO DE CARVALHO PAIS*
}

Resumo: O que nos faz enunciar proposições que parecem saber o que não está presente? Esta questão e o que Wittgenstein escreveu, em 1937, sobre a causalidade no MS 119 guiam o estudo que, assim confinado, empreendo da primeira parte das suas Investigações Filosóficas. As conexões causais firmadas na experiência, sob a forma de previsão ou conjectura empírica, são o que habitualmente é tomado como explicação do que parece saber o que não está presente em proposições como sejam as de expectativa, desejo ou justificação. Subjacente a este tipo de proposições, diz-nos Wittgenstein, não estão, todavia, crenças causais, mas antes crenças julgadas certezas para as quais não existe fundamento. Devemo-las somente ao jogo de linguagem. Começa assim a delinear-se o que viria a merecer uma especial reflexão filosófica nos seus últimos anos de vida, cujas observações foram coligidas e publicadas postumamente no livro Da Certeza.

Palavras-chave: causalidade - experiência - expectativa - desejo - intuição crença - certeza - jogos de linguagem.

Abstract: What makes us enunciate propositions that seem to know what is not present? This question and what Wittgenstein wrote, in 1937, about causality in MS 119 guide the study, so confined, that I undertake of the first part of his Philosophical Investigations. The causal connections predicated on experience, in the form of empirical prediction or conjecture, are what is usually taken as an explanation of what seems to know what is not present in propositions such as those of expectation, desire, or justification. Underlying this kind of propositions, Wittgenstein tells us, are not, however, causal beliefs, but beliefs judged as certainties for which there is no foundation. We owe them only to the language-game. It starts to become visible

* Faculdade de Ciências Sociais e Humanas da Universidade Nova de Lisboa. 
what would merit a special philosophical reflection in his last years of life, whose remarks were collected and posthumously published in the book On Certainty.

Keywords: causality - experience - expectation - desire - intuition - belief certainty - language-games.

No §437 das Investigações Filosóficas (IF), Wittgenstein refere-se implicitamente à causalidade do seguinte modo:

O desejo já parece saber o que o satisfará ou satisfaria; a proposição, o pensamento, já parece saber o que a tornará verdadeira, mesmo que isso não esteja presente! Donde provém esta determinação daquilo que ainda não está presente? Donde provém esta exigência despótica? (“A dureza da necessidade lógica").

Este estudo propõe-se analisar, na primeira parte das IF, como é que a relação de causa e efeito subjaz ao que, não estando presente, faz a proposição parecer saber o que a tornará verdadeira. O que está em questão, numa primeira abordagem, é a causalidade poder constituir esse tal saber, quando o que parece saber-se como verdadeiro é o efeito não presente no que se sabe ou prevê a partir do que se supõe ser a sua causa; ou é a causa não presente no que se sabe do seu pressuposto efeito. Mas a análise gramatical deste saber remete-nos para o fundamento do próprio nexo causal, que mais não é que uma crença que se manifesta em diferentes géneros de proposições. A exigência lógica de investigar a origem da "determinação daquilo que ainda não está presente" leva-nos, por fim, a interrogar o fundamento da própria crença.

O estudo é, assim, desenvolvido em duas partes principais. Dedicarei a primeira à apresentação de alguns exemplos das IF de análise desse saber derivado da relação de causalidade presumida, que tornará as proposições verdadeiras. Exemplos esses que, sob a forma do uso de palavras e de proposições de expectativa, desejo e justificação, são manifestações de crenças. Na segunda parte tratarei da crença e do seu fundamento. A descrição que Wittgenstein faz deste fundamento permitirá compreender como de facto se constitui esse saber que tornará a proposição verdadeira.

Wittgenstein investiga directamente o uso da conexão de causa e efeito na linguagem, na sua relação com a certeza e a dúvida, num conjunto de observações incluídas no MS 119, escritas entre 24 de Setembro e 29 de Outubro de 1937, num período que prepara a escrita da primeira parte das $\mathrm{IF}^{1}$.

1 Considerei aqui a tradução do original alemão para inglês, realizada por Peter Winch, sobre o título "Cause and Effect: Intuitive Awareness". Será esta tradução que seguirei e é partir dela que farei a minha própria tradução para português. As referências a este texto terão a indicação $\mathrm{CE}$. 
Estas observações revelam-se particularmente úteis para o estudo da questão colocada no mencionado $\$ 437^{2}$.

\section{Manifestações do que parece saber o que não está presente}

\subsection{Sentido da palavra e expectativa}

Há certas coisas que nos levam a esperar um determinado desempenho ou resultado, como se não fosse de todo possível esperar delas outra coisa. Uma expectativa, que não é uma previsão causal, já que aqui não há lugar ao esforço de inferência, não coloca em dúvida a infalibilidade da função dessas coisas. Parecem estar em si completamente determinados os seus efeitos.

Assim se passa com certas imagens que nos levam, aparentemente sem hesitar, a determinar do que são capazes os seus objectos:

A máquina como símbolo do seu efeito: a máquina, podia eu começar por dizer, parece já ter em si o efeito. O que é que isto quer dizer? Ao conhecermos a máquina, tudo o resto, isto é, os movimentos que ela fará, parece já estar completamente determinado. [...] (IF, §193)

É deste modo que Wittgenstein dá início ao exemplo paradigmático da máquina como símbolo do seu efeito. Este tem um conteúdo significante definido que determina previamente a operação de uma máquina. A imagem da máquina parece sempre suscitar o modo geral como ela opera, não compreendendo, designadamente, a possibilidade efectiva da disfunção ou inoperância. A "máquina" parece não ser afectada pela contingência, como se o futuro não pudesse surpreender o significante, e estivéssemos seguros do que ele nos reserva (cf. IF, §193).

Ao contrário de uma máquina real, os efeitos do seu símbolo não são previsíveis, por estarem totalmente determinados ${ }^{3}$. A máquina como instrumen-

2 Na composição das observações que vêm a constituir CE omitiu-se uma observação que foi incluída nas IF, §415. Esta observação é, no entanto, essencial para percebermos que a necessidade causal tem que ver com a história natural do homem, isto é, com a nossa actuação segundo práticas (regras do jogo de linguagem) que tornam natural essa necessidade. (Ver van Gennip 2010.)

3 A predeterminação da operação da máquina como símbolo deve ser entendida apenas como uma forma de descrição, e, por isso, diversa da determinação causal dos movimentos de uma máquina real. É no sentido gramatical que se deve compreender esta determinação, de modo a não confundir o símbolo do movimento com a produção do mesmo. Ou seja, do ponto de vista da lógica, a determinação visada é a do sentido da máquina como símbolo. (Ver Baker e Hacker 2009, 108.) 
to concreto pode avariar, quebrar, deformar, e só a previsão de que assim não acontecerá nos pode dar a confiança no seu funcionamento normal - sendo a normalidade o que se pode esperar da história da experiência da sua operação, a qual mostra que a inoperância ou o movimento disfuncional não é a regra. Quanto à "máquina", ainda que utilizada como símbolo de um modo particular de operar, não tem história pela mesma razão que o seu futuro é necessário. É deste modo simbólico que os movimentos da máquina estão presentes na sua imagem. Razão pela qual conhecemos toda a aplicação de uma palavra no que sabemos sobre o que ela designa, de acordo com a compreensão que dela temos (cf. IF, $\S \S 195$ e 264).

Uma vez aprendido o sentido da imagem, isto é, fixado o sentido do símbolo de algo, este fica lógica e necessariamente determinado, de tal modo que a sua aplicação é presente à imagem. Não é a história da experiência com uma máquina, ao constatarmos que ela tem funcionado de maneira regular, que, como causa, nos leva a determinar o seu sentido - isto é, que ela tem um certo modo de operar considerado normal. Pelo contrário, a palavra "máquina" tem um sentido previamente determinado que contém em si todas as possibilidades da sua aplicação ${ }^{4}$. Isto, obviamente, é algo bem diverso de dizer que essa determinação resulta da sua definição, a qual fixaria o seu sentido (ver IF, §258). Qualquer definição que delimite o conceito de uma palavra não compreende completamente as possibilidades da sua aplicação (cf. IF, §68). Por isso, apesar da nossa compreensão de uma palavra, o seu sentido reside sempre no seu uso (cf. IF, §197) .

A determinação das possibilidades do uso de uma palavra, como é o caso da palavra "máquina", dá origem a uma família de sentidos (cf. IF, §193). Entre esses usos, encontram-se aqueles que não necessitam da presença das coisas a que se referem. Tomemos o exemplo da palavra "vermelho": o modo como a usamos não implica necessariamente a presença de uma coisa vermelha, assim é quando notamos que o vermelho é ausente duma certa coisa presente, referindo-nos a esse vermelho como se ele pudesse ser o mesmo que está presente numa coisa vermelha. Contudo, o vermelho que dizemos ausente de uma coisa não é o mesmo que poderia ser dela uma qualidade (ver IF, $\S \S 57,443$ e 446). O sentido de uma palavra não está confinado ao uso que

${ }^{4} \mathrm{O}$ sentido de uma palavra é para Wittgenstein como um halo inextinguível em qualquer uma das suas aplicações, de tal modo que, como uma irradiação, preserva a totalidade das suas possibilidades de incidência: "Dizem-nos: 'Compreendes esta expressão, não é verdade? Bem, também estou a usá-la com o sentido que conheces.' [E não: ‘... com aquele sentido particular.'] Isto equivale a tratar o sentido como um halo que rodeia a palavra e que esta retém em qualquer tipo de aplicação.” (CV, 70).

5 Aliás, Wittgenstein admite mesmo que os nossos conceitos possam ser determinados pelo nosso interesse. (Ver MS 169, in UEFP, §323.) 
requer a sua correspondência a uma presença real, mas aponta para um espaço simbólico de possibilidades de aplicação. É, por isso, que o uso da palavra "dor", habitualmente considerada como o reconhecimento do sentimento de dor, envolve igualmente a inexistência desse sentimento (ver IF, §448). Conclui-se, deste modo, que o uso que se faz de uma palavra não necessita da presença da coisa a que se refere. $\mathrm{O}$ seu sentido, o seu uso, depende tanto da presença quanto da ausência do objecto real.

Daí que seja possível à linguagem manifestar expectativas sobre o que não está presente, como quem está insatisfeito com a sua ausência, ou melhor, com a sua exclusiva presença na consciência enquanto imagem (cf. IF, $\S \S 438$ e 452). A expectativa é, assim, uma antecipação da ocorrência de algo numa dada situação, mas não uma forma de previsão causal (ver IF, §581). Por exemplo, o que nos leva a prever uma explosão quando vemos uma mecha a arder em direcção a uma carga explosiva (ver IF, §576)? É possível ter como resposta que assim se passou na experiência repetida de situações similares. A previsão que aqui é feita parece fundar-se numa relação de causa e efeito confirmada empiricamente. Mas, de facto, o que temos nesta situação não envolve uma inferência; não houve um pensamento que nos levasse da causa ao efeito. Perante situações como esta, não elaboramos pensamentos, antes entramos num certo estado de expectativa ${ }^{6}$. A previsão que fazemos decorre desse estado. $\mathrm{O}$ que nos deixa nele tem que ver com aquilo em que acreditamos - de que falarei mais adiante.

As proposições que expressam expectativa, porque precisamente visam o que não está presente e sobre isso fazem uma previsão, têm nelas o que parece ser o saber do que as tornará verdadeiras:

Uma expectativa é feita de tal maneira, que o quer que depois ocorra tem que concordar com ela ou não. [...] (IF, §465)

Se a manifestação de uma expectativa estabelecer de forma clara as condições da sua realização, então ela sabe o que tem de ocorrer para que possa ser satisfeita. $\mathrm{O}$ mesmo se poderá dizer das proposições que exprimem desejo. Estas, ao darem voz a algo como um apetite, projectam no futuro, tal qual uma profecia, o que aspira à sua satisfação. Apesar de nada saberem sobre o futuro, ao sobre ele fazerem recair, como uma sombra, uma possibilidade ambicionada, também as proposições de desejo parecem saber o que as tornará verdadeiras (cf. IF, §461).

6 "Gramaticalmente, a expectativa é um estado [...]" (IF, §572). 


\subsection{Saber intuitivo e justificação}

Depois de ter apresentado o exemplo da máquina como símbolo, Wittgenstein, no parágrafo seguinte, aproveita para questionar a filosofia que faz recurso à ideia de que as coisas são de acordo com as suas possibilidades, sendo elas a causa cujo efeito é a sua realização. Segundo este modo de fazer filosofia, os movimentos da máquina seriam a realização das possibilidades desses movimentos, as quais estariam encerradas na máquina em si (ver IF, §194). Wittgenstein alerta-nos em CE - numa observação bastante semelhante à do $§ 193$ das IF - para a confusão que se gera quando se toma a máquina real pelo seu símbolo, o que "é" pelo que "é chamado"7. Na verdade, esta confusão poder-nos-ia levar ao erro de afirmar que, por assim dizer, o movimento da máquina real é presente e necessário e o do seu símbolo possível e contingente. É precisamente esta confusão que é tratada no $\$ 194$ das IF, onde é considerada como típica de quem faz filosofia.

Wittgenstein já nos tinha dito que a máquina como símbolo tem em si as possibilidades do seu movimento. Mas nunca que a máquina em si contém essas possibilidades. Neste último caso, as possibilidades não se referem nem ao movimento como tal, nem às condições físicas necessárias à operação de máquina, susceptíveis de se poderem mostrar, mas antes, a qualquer coisa que ele chama "sombra do próprio movimento", isto é, algo que não sendo a realidade, um facto da experiência, é semelhante a ela (cf. IF, §194) Mas, afinal, donde vem esta imagem de que a máquina tem em si as suas possibilidades? Parece que lhe subjaz uma necessidade de encontrar a causa para todos os supostos efeitos que conhecemos - uma necessidade de justificação. Por que é que a máquina se movimenta? Se a máquina se move, qual é causa desse movimento? Tem de haver uma conexão a algo que produza esse movimento, mesmo que isso não se possa mostrar. Confere-se, assim, uma designação a certa coisa de que não temos experiência e que presumimos ser causa de um efeito conhecido?.

7 CE, $401-26.9 .[37]$.

8 Baker e Hacker vêem nesta sombra da realidade uma critica não só a uma certa concepção de possibilidade como também a outros conceitos, designadamente, os que são atributos intencionais da mente, como sejam a expectativa, desejo, crença, vontade, e, acrescentaria eu, intuição. Ver 2009, 111.

9 Kim van Gennip estabelece, como ilustrações da confusão mencionada, um paralelo entre a máquina como símbolo e as sementes e as plantas que delas nascem, ambos exemplos referidos em CE (373-4 e 399-401). Com efeito, as sementes são encaradas como tendo em si mesmas as plantas que delas hão-de surgir, tal como a máquina tem em si os movimentos por vir. Em ambos os casos, a confusão decorre de tomar uma relação conceptual como sendo uma relação real. Ver 2010, 151-2. 
Mas, se não é a experiência que nos mostra as possibilidades como tais da máquina, então como é que podemos ter conhecimento delas? Poder-se-ia dizer que é através da intuição que conhecemos a causa. Ela dar-nos-ia a conhecer o que escapa à experiência "Do mesmo modo grosseiro que sei o que significa "ver um corpo de todos os seus lados de uma só vez"' ${ }^{10}$. Todavia, como consciência imediata de algo, a palavra intuição parece sofrer de problema igual ao da ideia das possibilidades da máquina real; também ela, que não é um estado, mais parecendo uma faculdade, é a causa suposta de um dado efeito - o conhecimento; são, pois, como sombras da realidade. Ambas poderiam encontrar-se na situação que Wittgenstein assinala ao citar Fausto I de Goethe ${ }^{11}$ :

Justamente quando o conceito falha,

Aí vem a palavra dar um jeito.

Além do mais, seja o que for que designamos por intuição, ignoramos se o que ela nos dá é verdadeiro (cf. IF, §213). Por tudo isto, Wittgenstein conclui que a intuição é uma desculpa necessária e, como tal, o conhecimento intuitivo da causa é "de uma maneira ou de outra saber a causa"12.

Enfim, ficamos, deste modo, sem saber o que são as possibilidades que constituem a máquina em si, responsáveis pela sua operação. Como este conceito de possibilidades parece ser do mesmo género de outros conceitos aparentados, como sejam potência ou força, característicos de certo discurso filosófico, pode-se afirmar que também sobre eles recai o mesmo desconhecimento do seu fundamento. Talvez seja por esta razão que Wittgenstein tece uma dura crítica ao modo como se faz filosofia, caracterizando-o como selvagem, próprio de homens primitivos (ver IF, §194).

Assim, a suposta conexão causal, de carácter intuitivo, uma vez estabelecida, é ou uma forma de tentativa de explicação do que aconteceu, perante uma experiência que não se justifica a si mesma, ou de antecipação de um acontecimento futuro a partir de um suposto conhecimento a priori do que o determinará. Quer como justificação, quer como uma espécie de profecia, o saber intuitivamente a causa é mais um caso que dá origem a proposições que se tornarão verdadeiras (ou falsas) com a verdade (ou falsidade) do que parecem saber sobre o que não está presente. Como uma espécie de profecia, este saber pode vir a testar a sua verdade à maneira de uma expectativa: a sua satisfação dependerá da sua confirmação. Já como uma justificação de um

$10 \mathrm{CE}, 393-18.10$.

11 CE, 393 - 17.10. Utilizou-se a tradução para português de João Barrento (1999, 114, 1995-96).

12 Cf. CE, $393-18.10$. 
acontecimento passado, precisamente porque ele nunca voltará à presença como experiência, a sua verdade depende da prova que a certifique e da força da sua evidência; seja como for, será sempre um fruto da convicção.

\section{Fundamentação do que parece saber o que não está presente}

\subsection{Saber como crença}

As proposições através das quais manifestamos o estado de expectativa ou desejo em que nos encontramos dependem do que acreditamos. Esperamos certo acontecimento porque acreditamos que ele assim acontecerá. $\mathrm{E}$ é ainda a crença que suporta as proposições que tentam justificar o acontecido, mesmo quando este defraudou a nossa expectativa. O que acreditamos é justamente aquilo que já parece saber o que tornará verdadeira as proposições de expectativa e justificação. Mas como é que chegamos a acreditar? O que é que nos leva a crer para podermos esperar ou desejar o que não está presente ou aceitar certas justificações? O que é que nos convence?

Poderíamos considerar que as crenças se constituem como uma elaboração do pensamento, uma vez que o que é pensado pode vir a revelar-se útil na vida prática (cf. IF, §470). Caberia, deste modo, ao pensamento fundar a crença com base naquilo que o alimenta - a experiência; é o pensar a experiência repetida que nos levaria à formação da crença, precisamente porque nos tem dado provas da sua utilidade. E, contudo, não é claro que a experiência anterior possa ser fundamento para a previsão do que possa vir a ocorrer (ver IF, §480). Na verdade, essas experiências dão-nos a conhecer as causas do que acontece, e até reacções a causas, como quando alguém se queima ao tocar na chapa aquecida do fogão ou a dor que sente quando crava um lápis na sua mão (ver IF, §§477-8). É, pois, simples e natural o pensamento que infere da repetição das experiências com um dado padrão de relação causa e efeito que este continuará a repetir-se indefinidamente. A repetição torna provável a ocorrência do acontecimento.

Todavia, diz-nos Wittgenstein que a probabilidade de ocorrência do acontecimento é tão bom fundamento quanto qualquer outro que se baseie num padrão infundado de bom fundamento (cf. IF, §482). Com efeito, não encontramos fundamento para as crenças nas observações da experiência que permitiram por inferência lógica concluir pela sua necessidade, como igualmente não o encontramos nas premissas de uma dedução lógica, em que elas seriam a sua consequência necessária (cf. IF, §481). A crença não é, de todo, uma consequência do pensar, embora se possa pensar a crença. Por esta razão, os conceitos de crença e expectativa têm entre si afinidades que não existem com o conceito de pensar (cf. IF, §574). Só aqueles conceitos parti- 
lham do que "parece saber" o que não está presente. Convém notar que isto não significa que descuremos a experiência e o que ela nos permite antecipar, mas sim que a previsão que a partir dela fazemos não é de carácter causal, ela não é um efeito cuja causa é a história da nossa experiência passada ${ }^{13}$.

\subsection{Sentimento de certeza}

Mas por que é que uma crença é como um "parecer saber"? Simplesmente, porque é tida como saber, no sentido de que está acima de qualquer suspeita. De que ninguém duvida de que o fogo queima prova-o o medo de ser queimado (ver IF, $\S \S 437$ e 474). A crença, esse "saber" do que não está presente, não convive de modo nenhum com a dúvida, mas isso não se deve, como vimos, ao facto de saber efectivamente o que é a causa do que seja. A certeza que lhe subjaz não é esse saber. Ela não decorre da evidência incontestável, nem é um resultado de um raciocínio cuja conclusão é indefectível. Se não é o pensamento que engendra a crença mas a certeza, esta, obviamente, não é um fruto do pensar.

Para Wittgenstein, a certeza poderia ser vista como uma sensação ou um sentimento onde radicaria a crença (cf. IF, $\S \S 578$ e 607). Talvez por essa razão, diz-nos ele, seja difícil darmo-nos conta de que, na realidade, acreditamos quando julgamos saber (ver IF, §587) e as nossas proposições que já parecem saber o que, não estando presente, as tornará verdadeiras vêm imbuídas do sentimento que confere verdade às suas palavras (ver IF, §544).

O $§ 607$ das IF procura investigar o que possa ser esta espécie de sentimento de certeza ou convicção. Não é um súbito assomo de compreensão. Parece ter mais que ver com a sensação de calma, segurança e confiança, como se fosse uma atmosfera especial. Wittgenstein reconhece que, no entanto, para tudo é possível construir uma atmosfera, como forma de dar nome àquilo que tem um "carácter indescritível" (ver IF, §609)14. Ou poderá apenas corresponder a uma injunção para substituir o sentimento de estranheza com o que é desconhecido pelo sentimento de certeza (ver IF, §596)? $\mathrm{Na}$ verdade, Wittgenstein não tem dúvidas em afirmar que a certeza não é uma espécie de sentimento, e que o importante na certeza é o modo de acção e, naturalmente, também é o modo de acção o mais importante na crença ${ }^{15}$.

13 Cf. CE, 375 - 26.9.37.

14 Esta atmosfera especial não é algo que esteja associado ou preso ao objecto ou evento sobre o qual temos certeza, mas como que lhe pertence. Ela nomeia o que não conseguimos atribuir significado, não conseguimos descrever. E daí a sua intransitividade. Ver Hacker 1996, 523-7.

15 Cf. MS 169 (cerca de 1949), §§ 156-7 in Últimos Escritos Sobre a Filosofia da Psicologia. 
Uma coisa parece clara, que o que parece ser um sentimento de certeza e a verdade que pretensamente o acompanha não têm fundamento:

[...] E no que respeita à sensação de certeza: digo-me, muitas vezes, "Tenho a certeza de que são ... horas", num tom de voz mais ou menos seguro. Se me perguntas pelo fundamento desta certeza, não tenho. [...] (IF, §607)

Conclui-se, deste modo, que a nossa crença não tem fundamento e, não obstante, não duvidamos dela. Actuamos com toda a certeza que lhe é necessária. A práxis exclui a dúvida.

\subsection{Certeza e jogos de linguagem}

Se não conseguimos encontrar fundamento para a crença, se não há nada que nos impeça de questionar as nossas sensações de certeza, por que é que no lugar da dúvida se impõe a certeza? Na realidade, o mais das vezes, no correr dos dias, não nos faltariam razões para duvidar. Por exemplo, não temos como saber se um resfriado se agravaria ou duraria mais tempo se não ingeríssemos um medicamento apropriado; ou como saber em que momento exacto o nosso peso se alterou, a não ser verificar que entre duas pesagens o peso aumentou ou diminuiu ${ }^{16}$. Preferimos, no entanto, entregar-nos à certeza, mas não de maneira a que se possa dizer que o fazemos sem justificação. Com efeito, as nossas certezas são reforçadas pelo êxito que elas mesmas nos asseguram (ver IF, §324).

Considera-se infalível a indução a partir da experiência anterior; é essa experiência a causa da nossa certeza (ver IF, §325). E quando somos por ela surpreendidos, desmentindo a nossa expectativa, não nos faltam razões justificativas que voltam a suportar esta mesma expectativa no futuro. Essas razões, diz-nos Wittgenstein, como justificações à luz da experiência, estão limitadas pelo que ela nos dá a conhecer (cf. $\S \S 326$ e 485). De facto, a experiência não se justifica a si mesma, isto é, são sem fundamento as razões últimas nela suportadas. Por isso, quando as justificações se nos acabam, simplesmente partimos para a acção (cf. IF, §211) ${ }^{17}$. Para actuarmos temos

16 Ver CE, 401 e $403-28.9$..

17 Wittgenstein afirma o carácter injustificável e radical da nossa actuação, sendo ela toda a certeza que temos: "Nada do que fazemos se pode defender de uma maneira absoluta e definitiva. Apenas por referência a qualquer outra coisa que não se ponha em dúvida. Isto é, não se pode oferecer qualquer razão para que ajam (ou tenham agido) desta maneira, excepto que, pelo facto de o fazerem, ocasionam esta ou aquela situação, que tem de ser, de novo, aceite como um fim." (CV, 33). 
que deixar de nos questionar e abandonar a dúvida para nos armarmos na certeza. De tal modo, que a cultura de um povo pode ver-se nas justificações que acaba por aceitar (cf. IF, §325).

Chegados aqui, é indeclinável a pergunta sobre o que nos faz viver segundo um dado sistema de crenças, como é que ele se instala, e o que é que a ele nos prende. Este questionamento parece ser essencial ao projecto filosófico de Wittgenstein:

[...] É esta prisão nas nossas regras que queremos compreender, isto é, ter dela uma visão panorâmica. [...] (IF, §125)

As regras aqui mencionadas dizem respeito às que são praticadas nos jogos de linguagem. Estes jogos obedecem a regras, muitas vezes implícitas, que se aprendem, desde a infância, por adestramento no entrecruzar da acção com a linguagem (ver IF, §§7 e 54). Não duvidamos dessas regras e das formas de vida que são geradas pelos jogos da linguagem (cf IF, §19). Com efeito, a vida que levamos, na medida em que somos nós a dar-lhe o sentido, desenrola-se na relação das palavras com o seu contexto de uso significante, precisamente as palavras que constituem a linguagem em que fomos adestrados na sua relação ao mundo em que actuamos ${ }^{18}$. A nossa forma de vida radica, pois, nas regras que seguimos como práxis, e seguimo-las sem crer que agimos deste modo (cf. §202).

É na prática desses jogos que podemos ver o modo como a linguagem faz recurso à relação de causa e efeito. Nas observações do MS 119, a que temos vindo a recorrer, Wittgenstein tem um conjunto de ideias explícitas que nos podem ajudar à compreensão genérica deste jogo de linguagem. É tão-só este objectivo que guia a selecção e a organização com um determinado sentido que delas de seguida fazemos. Bem sabemos o quão adversa é a sistematização para o estilo deste filósofo, pelo que, evidentemente, não pretendemos, de modo algum, que o alinhamento que damos a estas ideias constitua, na realidade, um seu raciocínio que se possa encontrar nas referidas observações. Eis então essas ideias expressas na minha própria formulação:

1. Quando, face ao facto de para tudo termos de encontrar uma causa, Wittgenstein nos diz que "procurar por uma causa" é um jogo que consiste numa certa prática ou num certo método, ele está a referir-se aos jogos de linguagem ${ }^{19}$.

18 Adoptamos aqui a definição que James Conant dá de jogo de linguagem, justamente como aplicação de palavras e proposições em contexto de uso significante. (Ver Conant 1998.)

19 Ver CE, $395-20.10$ - e $399-22.10$. 
2. Nestes jogos, a crença vem revestida da linguagem da causalidade, que com segurança induz da experiência causa certa. Não duvidamos da causa que encontramos, pois o jogo, na sua forma básica, aquela segundo a qual agimos, não admite a dúvida ${ }^{20}$.

3. E é logo assim no jogo de linguagem primitivo - é a certeza que constitui a formação das práticas, isto é, das regras do jogo; a incerteza inibiria a acção. Quando somos adestrados a articular as palavras com a acção, entramos sem duvidar numa forma de vida ${ }^{21}$.

4. A dúvida, por tudo isto, é algo de muito estranho ao jogo, sobretudo quando, seguindo as regras, a explicação para a superar não é bem sucedida. A dúvida que não se inclua no próprio jogo da linguagem lança-nos para fora dele, faz-nos abandonar uma certa "ordem" em direcção ao desconhecido. Mas uma tal situação excepcional é um momento de hesitação que resolvemos voltando à certeza, que é um regresso à acção ${ }^{22}$.

Este conjunto de ideias seleccionadas das referidas observações do MS 119 será aprofundado por Wittgenstein no Da Certeza, livro de publicação póstuma, que reúne observações que escreveu nos últimos anos da sua vida, até ao seu falecimento, em 1951. Aí podemos perceber melhor de que modo os jogos de linguagem alicerçam o que parece saber o que não está presente, de tal modo que tornará verdadeiras certas proposições.

\section{Referências}

Baker, G. P., e P. M. S. Hacker. 2009. Rules, Grammar and Necessity: Essays and Exegesis of \$\$185-242 - Volume 2 of An Analytical Commentary on the Philosophical Investigations, second, extensively revised edition by P. M. S. Hacker. Oxford: Wiley-Blackwell.

Conant, J. 1998. "Wittgenstein on Meaning and Use", Philosophical Investigations, 21, 3: 222-50.

Goethe, J. W. 1999. Fausto. Lisboa: Relógio de Água.

Hacker, P. M. S. 1996. Wittgenstein: Mind and Will - Volume 4 of an Analytical Commentary on the Philosophical Investigations, Oxford: Blackwell Publishers.

van Gennip, K. 2010. "On the Origin and Composition of 'Cause and Effect: Intuitive Awareness"', in Language and World-Part One: Essays on the Philosophy of Wittgenstein, eds. Volker A. Munz, Klaus Puhl e Joseph Wang. Frankfurt: Ontos Verlag.

\footnotetext{
20 Ver CE, 373 - 24.9, -, 377 - 12.10. - e 397 - 21.10.

21 Ver CE, 381 - 14.10 - e 397 - 22.10.

22 Ver CE, $379-13.10$.
} 
Wittgenstein, L. 1987. Investigações Filosóficas, in Tratado Lógico-Filosófico e Investigações Filosóficas, trad. M. S. Lourenço. Lisboa: Fundação Calouste Gulbenkian. (IF).

-----. 1993. "Cause and Effect: Intuitive Awareness", in Philosophical Occasions: 1912-1951, eds. J. C. Klagge e A. Nordmann. Indianapolis: Hackett Publishing Company. (CE)

-----. 2000. Cultura e Valor, trad. J. Mendes. Lisboa: Edições 70. (CV)

-----. 2007. Últimos Escritos Sobre a Filosofia da Psicologia, trad. A. Marques, N. Venturinha e J. T. Proença. Lisboa: Fundação Calouste Gulbenkian. (UEFP) 